\title{
APPLICATION OF MONTE CARLO FILTER FOR COMPUTER VISION-BASED BAYESIAN UPDATING OF FINITE ELEMENT MODEL
}

\begin{abstract}
In this paper we describe Bayesian inference-based approach to the solution of parametric identification problem in the context of updating of a finite element model of a structure. The proposed inverse solution is based on Monte Carlo filter and on the comparison of structure displacements extracted using digital image correlation method during a quasi-static loading and the corresponding displacements predicted by finite element method program. Our approach is applied to the problem of material model parameter identification of an aluminum laboratory-scale frame. The results are also verified by comparing the Monte Carlo filter-based solution with the analytical solution obtained using Kalman filter.
\end{abstract}

Keywords: Bayesian inference, parametric identification, model updating, computer vision, Monte Carlo filter

\section{ZASTOSOWANIE FILTRÓW MONTE CARLO DO OPARTEGO NA WIDZENIU KOMPUTEROWYM BAYESOWSKIEGO STROJENIA MODELU MES}

\begin{abstract}
Artykut przedstawia zastosowanie podejścia opartego na wnioskowaniu bayesowskim do problemu identyfikacji parametrycznej w kontekście strojenia modelu MES konstrukcji. Proponowane rozwiazanie odwrotne opiera sie na filtrze Monte Carlo oraz porównaniu przemieszczeń konstrukcji otrzymanych metoda korelacji obrazów cyfrowych podczas quasi statycznej próby obciażeniowej i odpowiadających im przemieszczeń przewidywanych przez program oparty na metodzie elementów skończonych. Nasze podejście zostało zastosowane do identyfikacji parametru modelu materiatu aluminiowej ramki laboratoryjnej. Otrzymane wyniki porównano z wynikami otrzymanymi za pomoca filtru Kalmana.
\end{abstract}

Stowa kluczowe: wnioskowanie bayesowskie, identyfikacja parametryczna, widzenie komputerowe, strojenie modelu, filtr Monte Carlo

\section{INTRODUCTION}

Model updating or model calibration is an important step in the development of computational models and it is an integral part of the verification, validation and uncertainty quantification (Oden et al. 2010; Roy and Oberkampf 2011). Model calibration ensures that the model predictions fit the corresponding observations better. It is done by identification of selected model parameters like elastic moduli using experimental observations and inverse analysis. This calibration process is often difficult because of the uncertainties caused by measurement errors and limited number of observations. The unavoidable uncertainty has to be treated mathematically using one of the well-developed representations like for example fuzzy sets theory, Dempster-Shafer theory or probability theory (Babuška et al. 2008).

In the last few years Bayesian updating and validation came into the forefront of interest (Mares et al. 2006). Bayesian updating is a probabilistic approach to model updating process in which the uncertainty quantification is taken into consideration together with the prior knowledge about model parameters. Bayesian updating is also sequential in nature and is sometimes called Bayesian filtering. For example the well-known extended Kalman filter (EKF) was applied by Maier et al. for stochastic estimation in fracture mechanics (Maier et al. 2006). Although EKF has been widely applied, it is only reliable for almost linear models. For highly-nonlinear models, Monte Carlo filter may be a viable alternative. Nasrellah and Manohar proposed a strategy for combining finite element method and Monte Carlo filter to tackle the problem of structural system parameter identification (Nasrellah and Manohar 2011).

There is also a growing interest in using optical measurements for solving parametric identification problems encountered in the context of mechanics of structures and materials. Furukawa and Pan (Furukawa and Pan 2010) applied computer vision-based full-field measurements and Kalman filter for on-line characterization of anisotropic materials.

Reliable model predictions are the key elements of structural health monitoring (SHM) systems. Moreover, structural health monitoring applications rely heavily on the sequential identification of component or structure states and/or parameters for damage detection, localization and prognosis. Ching et al. compared the particle filter and the extended Kalman filter in the problem of Bayesian state and parameter estimation of uncertain dynamical systems (Ching et al. 2006).

In this paper we describe a Bayesian approach to updating of a structural finite element model. The updating is based on computer vision-based measurements of structure displacements and Monte Carlo filter estimation.

The paper is organized as follows. In the second section we give a short introduction to dynamic Bayesian networks and Monte Carlo filters. The next section presents the example application of our approach to an identification problem. In the fourth section we describe the computer experiments and results. The last section contains final remarks.

\footnotetext{
* Institute for Computational Civil Engineering, Cracow University of Technology, Warszawska 24, 31-155 Cracow, Poland; MTekieli@L5.pk.edu.pl;
} MSlonski@L5.pk.edu.pl 


\section{PARTICLE FILTER FOR SEQUENTIAL ESTIMATION}

Particle filter (PF) is usually introduced in the probabilistic context for inference in dynamic Bayesian networks. Dynamic Bayesian network (DBN) is a Bayesian network which represents a temporal probability model, see (Russel and Norvig 2010) for a very good introduction to DBNs. The well-known Kalman filter used to model linear discrete dynamic systems, is an example of dynamic Bayesian network with continuous variables and linear Gaussian conditional distributions. On the other hand, DBN can model arbitrary distribution in which the joint distribution over the sequence of $K$ observed variables $\mathbf{y}_{1: K}$ and state variables $\mathbf{x}_{0: K}$ is given by

$$
p\left(\mathbf{x}_{0: K}, \mathbf{y}_{1: K}\right)=p\left(\mathbf{x}_{0}\right) \prod_{k=1}^{K} p\left(\mathbf{x}_{k} \mid \mathbf{x}_{k-1}\right) p\left(\mathbf{y}_{k} \mid \mathbf{x}_{k}\right),
$$

where $p\left(\mathbf{x}_{k} \mid \mathbf{x}_{k-1}\right)$ is the transition model (here first-order Markov chain), $p\left(\mathbf{y}_{k} \mid \mathbf{x}_{k}\right)$ is the observation model and $p\left(\mathbf{x}_{0}\right)$ is the prior distribution of initial states. Figure 1 shows the Bayesian network structure corresponding to the first-order Markov process for the state variables and the observed variables conditioned on the state variables.

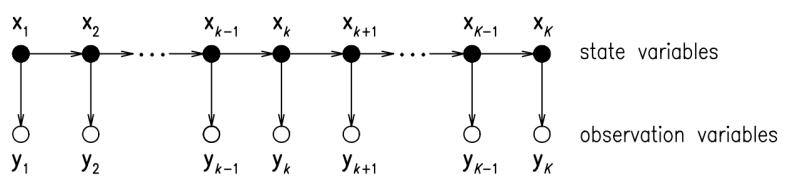

Fig. 1. Dynamic Bayesian network representing probabilistic dependence between state and observed variables

In the sequential estimation problems, we are mainly interested in recursive computations of the posterior distribution $p\left(\mathbf{x}_{k} \mid \mathbf{y}_{k}\right)$, but in general exact inference is intractable so different approximate methods have been developed so far. The most successful algorithm for approximate inference is based on sequential Monte Carlo sampling and approximating the posterior using $N$ particles to obtain the empirical distribution $P_{N}\left(\mathbf{x}_{k}\right)$.

The basic particle filter algorithm consists of the initialization of the variables and one "for" loop with four steps inside, see also figure 2 for the schematic. In the initialization phase a population of $N$ initial-state samples is created by sampling from the prior distribution $p\left(\mathbf{x}_{0}\right)$. Then in the main loop for each time step the prediction and update phases are repeated (Russel and Norvig 2010):

1) Particles are propagated forward by sampling the next state value $\mathbf{x}_{k}$, given the current value $\mathbf{x}_{k-1}$ for the particle, based on the transition model $p\left(\mathbf{x}_{k} \mid \mathbf{x}_{k-1}\right)$.

2) Each particle is weighted by the likelihood it assigns to the new evidence, $p\left(\mathbf{y}_{k} \mid \mathbf{x}_{k}\right)$.

3) Particles are resampled to generate a new population of $N$ particles. Each new particle is selected from the current population; the probability that a particular sample is selected is proportional to its weight (the new samples are unweighted).
4) Stopping criterion is checked (if not satisfied the first step of the loop is started again).

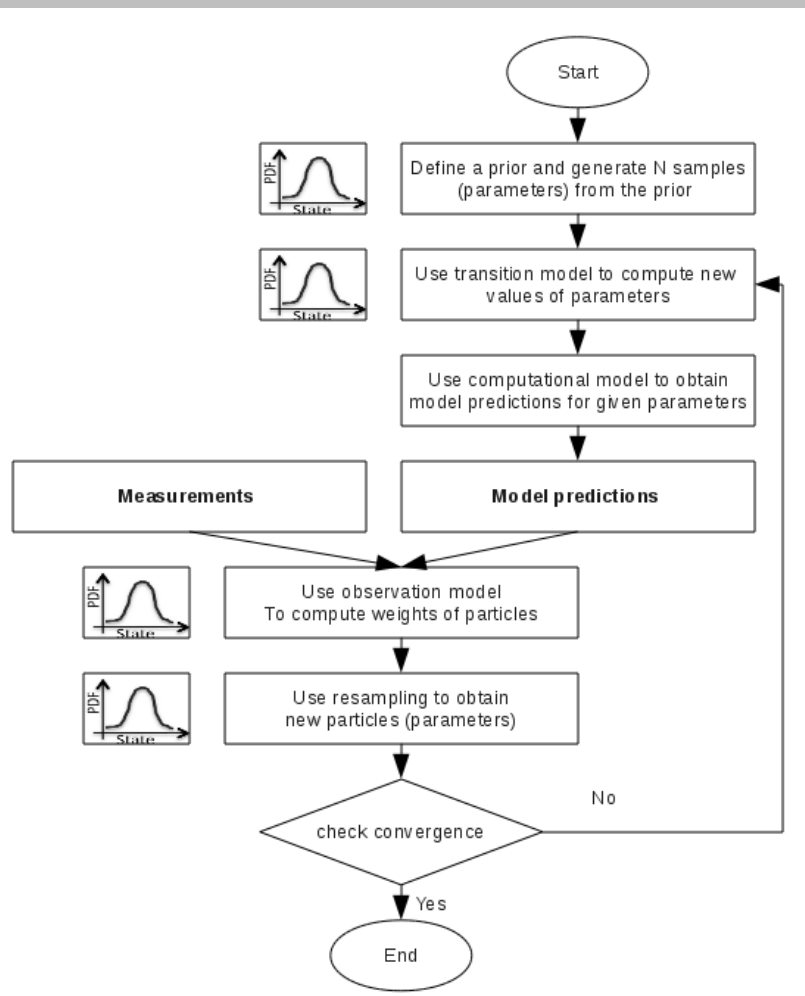

Fig. 2. Schematic description of basic particle filter algorithm

\section{EXAMPLE APPLICATION}

In this section we show how our approach can be applied for a finite element model updating of a laboratory frame shown in figure 3 (Miller 2011). The examined structure is a two-storey frame, made from an aluminum alloy with Young modulus $E=70.77 \mathrm{GPa}$ and Poisson ratio $v=0.3$. The height of the frame is $40 \mathrm{~cm}$ and the width is $48.0 \mathrm{~cm}$. The beams and columns have a rectangular cross-section $2.5 \times 0.6 \mathrm{~cm}$ and the columns are bolted to a steel basement.

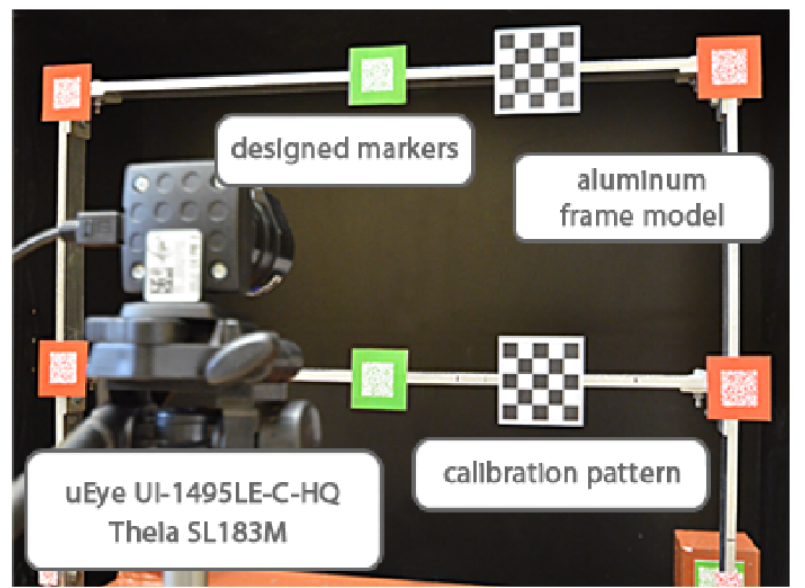

Fig. 3. View of two-storey aluminum frame and experimental stand 
In the experimental part of our work we performed several quasi-static experiments applying a concentrated force in the middle of the top beam or in the upper right corner (see the view of the experimental stand in figure 3 ). The value of the applied load was measured in near-real time by the digital force gauge Lutron FG-5000A connected to a laptop computer. During the experiments we also measured the horizontal and vertical displacements of selected frame nodes. The measurements were done using specially designed markers attached to the frame (see figure 4) and a computer vision-based system. The system was developed by the first Author with the aid of OpenCV Library (Bradski and Kaehler 2008).

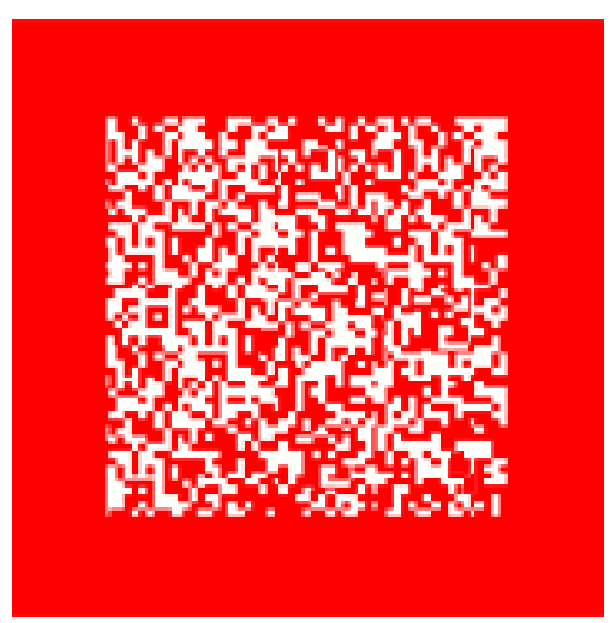

Fig. 4. View of specially designed marker

More details can be found in (Tekieli and Słoński 2013) The system was able to track in near-real time the positions of markers with the accuracy of about $0.15 \mathrm{~mm}$ by applying the digital image correlation (DIC) method.

In numerical experiments, we applied the finite element method. The frame was treated as a 2D model using standard 1D two-node frame elements (see the diagram of the frame FE model in figure 5). The FEM computations were implemented and carried out in our system.

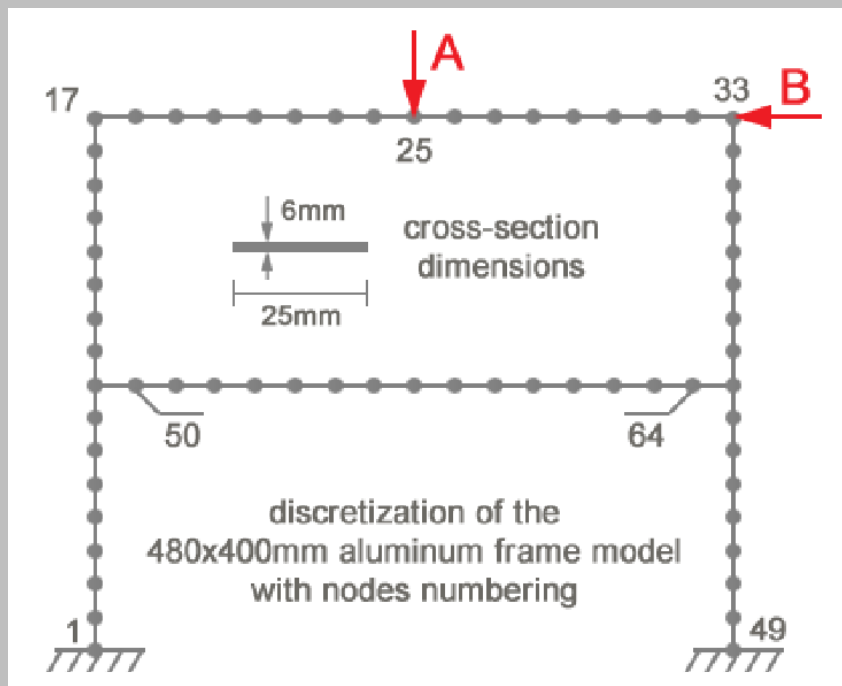

Fig. 5. Finite element discretization of 2D model of frame

\section{EXPERIMENTS, RESULTS AND DISCUSSION}

In this section we describe the experiments we conducted, show the results of the model updating and discuss the main findings. All numerical experiments were done using our computer application developed in $\mathrm{C}++$. The graphical user interface of the application is shown in figure 6.

Having the two sources of information about the frame displacements in near-real time, it was possible to solve the material model parameter identification problem using filtering. In our computer experiments, we applied the particle filter as the basic tool for the model updating and compared the results with the standard Kalman filter-based results. We assumed that the state vector $\mathbf{x}$ for both filters consisted of only one state variable $x_{k}$ which represented Young modulus in time step $k$. The observed variables $\mathbf{y}_{k}$ were the displacements of frame six points (with markers). For both filters, the transition model for the evolution of Young modulus was static, i.e. $x_{k}=x_{k-1}$. The prior distribution for the initial state was a normal density distribution $p\left(x_{0}\right)=\mathscr{N}\left(x_{0} \mid \mu, \sigma_{x}^{2}\right)$, with mean value $\mu=70 \mathrm{GPa}$ and standard deviation $\sigma_{x}=7 \mathrm{GPa}$.

The observation model was represented by a linear Gaussian conditional distribution

$$
p\left(\mathbf{y}_{k} \mid x_{k}\right)=\mathscr{N}\left(\mathbf{y}_{k} \mid \mathbf{y}_{k}^{F E M}\left(x_{k}\right), \boldsymbol{\Sigma}_{y}\right)
$$

where $\mathbf{y}_{k}^{F E M}\left(x_{k}\right)$ denotes the displacements of the frame points computed by FEM for the assumed Young modulus value and $\boldsymbol{\Sigma}_{y}=\sigma_{x}^{2} \boldsymbol{I}$ is the isotropic covariance matrix of measurement errors. All presented results were obtained for particle filters with $N=400$ particles representing Young modulus posterior distribution $P_{N}\left(x_{k}\right)$.

The results of two numerical experiments for Young modulus sequential estimation in the case of vertical force are given in figures 7 and 8 . The plots show the evolution of mean values of the posterior distributions for Young modulus, estimated using particle filters and Kalman filter (for the first experiment only).

There are also shown two horizontal lines that represent the reference value $E=70.8 \mathrm{GPa}$, taken from (Miller 2011), and the mean value computed for the values estimated for each measurement, respectively. In the first experiment, the mean value of Young modulus estimated by particle filter was $E=67.0 \mathrm{GPa}$ and the corresponding result for the Kalman filter was also $E=67.0 \mathrm{GPa}$.

These results are rather close to the reference value (the relative error less than 5\%). In the second experiment, the mean estimated value of Young modulus was $E=68.4 \mathrm{GPa}$. The plots also show the evolution of the measurement errors defined as the difference between DIC-based and FEM-based displacements of nodes. It is visible that the measurement errors are strongly correlated with the estimated values of Young modulus.

Figures 9 and 10 show the corresponding estimation results obtained for two experiments in the case of horizontal force. In the first experiment, the mean value of Young modulus estimated by particle filter was $E=70.3 \mathrm{GPa}$ and in the 
second experiment the mean estimated value of Young modulus was $E=70.4 \mathrm{GPa}$.

Note that in the case of horizontal forces, the estimated values are very close to the reference value (the relative error less than $1 \%$ ).

The smaller error is caused by the fact that the frame rigidity in the horizontal direction is about three times smaller than in the case of vertical force direction and also by the fact that the maximum accuracy of our DIC-based vision system is about 1 pixel in both directions.

Finally, the plots in figures 11 and 12 present the validation of the updated FE frame model in the form of the comparison of the displacements measured by the vision system and predicted by the updated model.

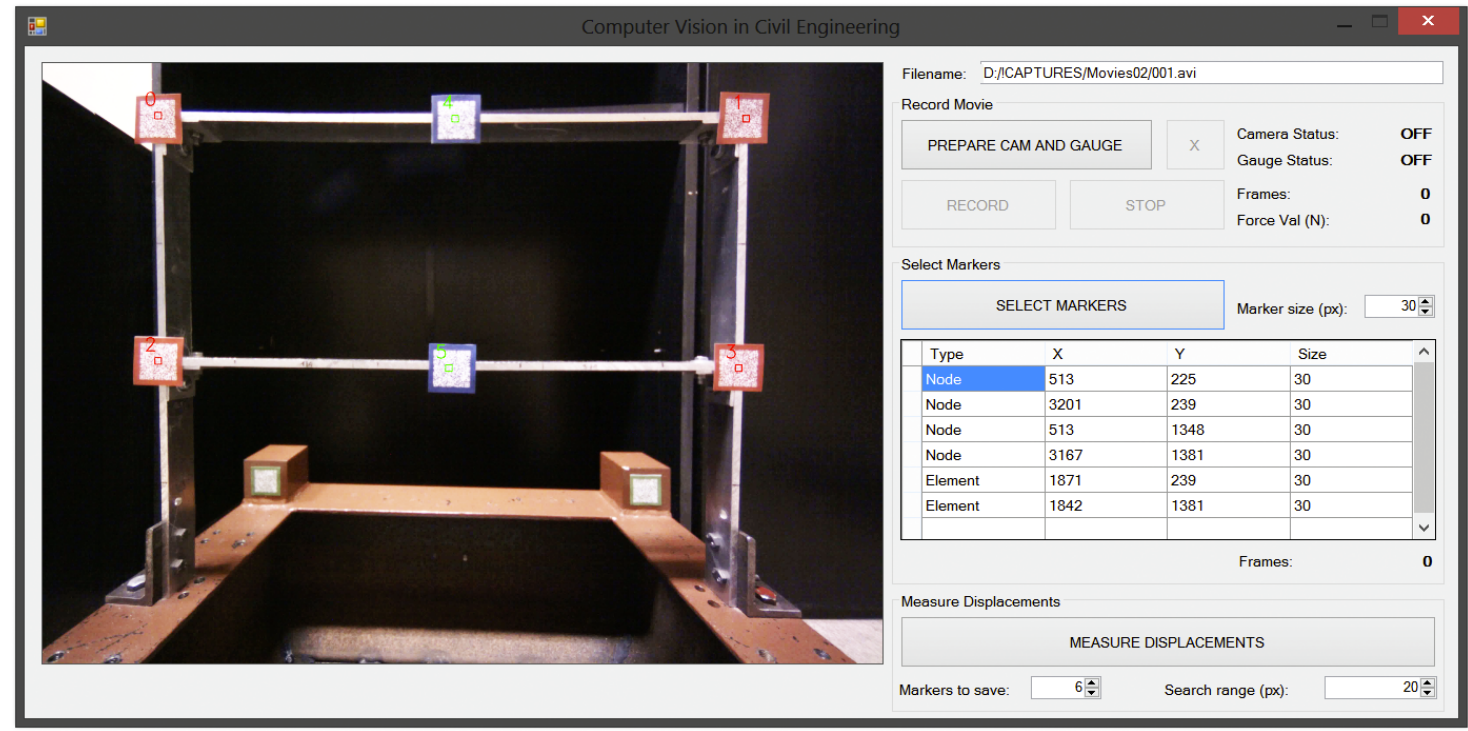

Fig. 6. View of application graphical user interface



Fig. 7. Plot of sequential estimation of Young modulus using Kalman filter and particle filter, in case of vertical force (first experiment) 


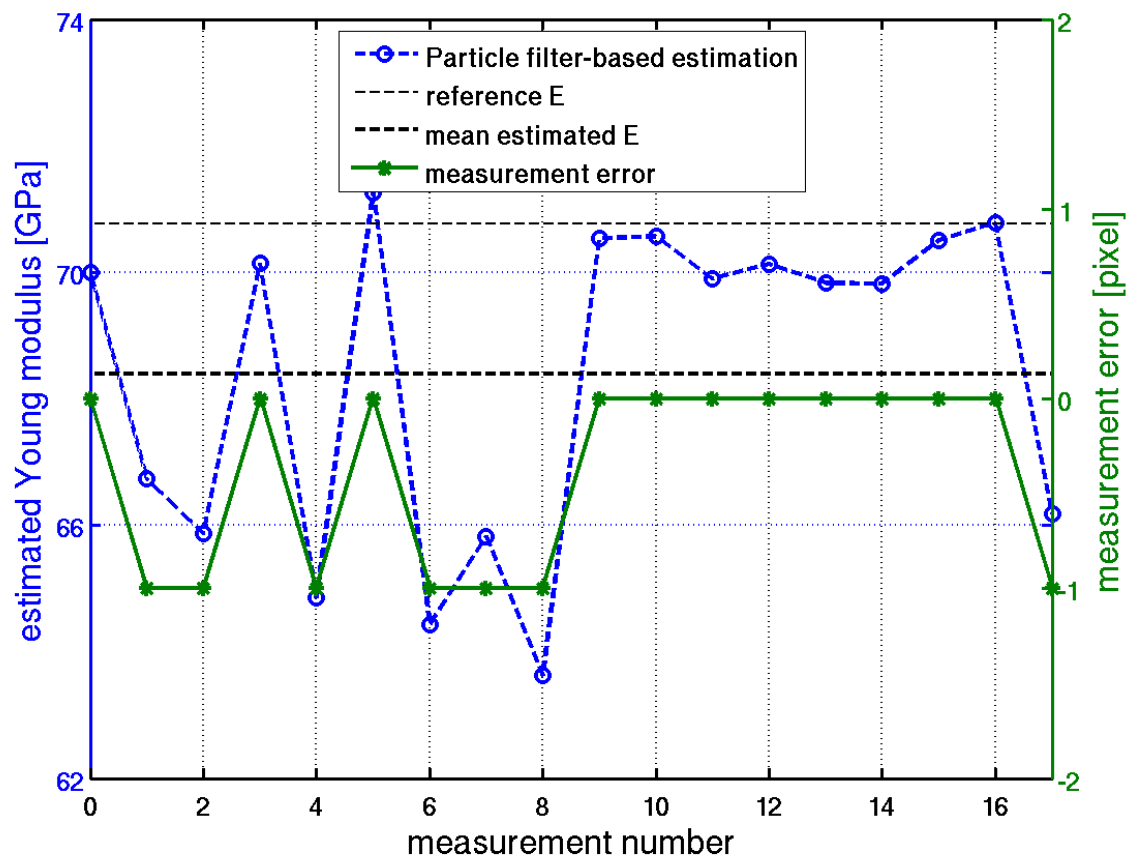

Fig. 8. Plot of sequential estimation of Young modulus using particle filter, in case of vertical force (second experiment)

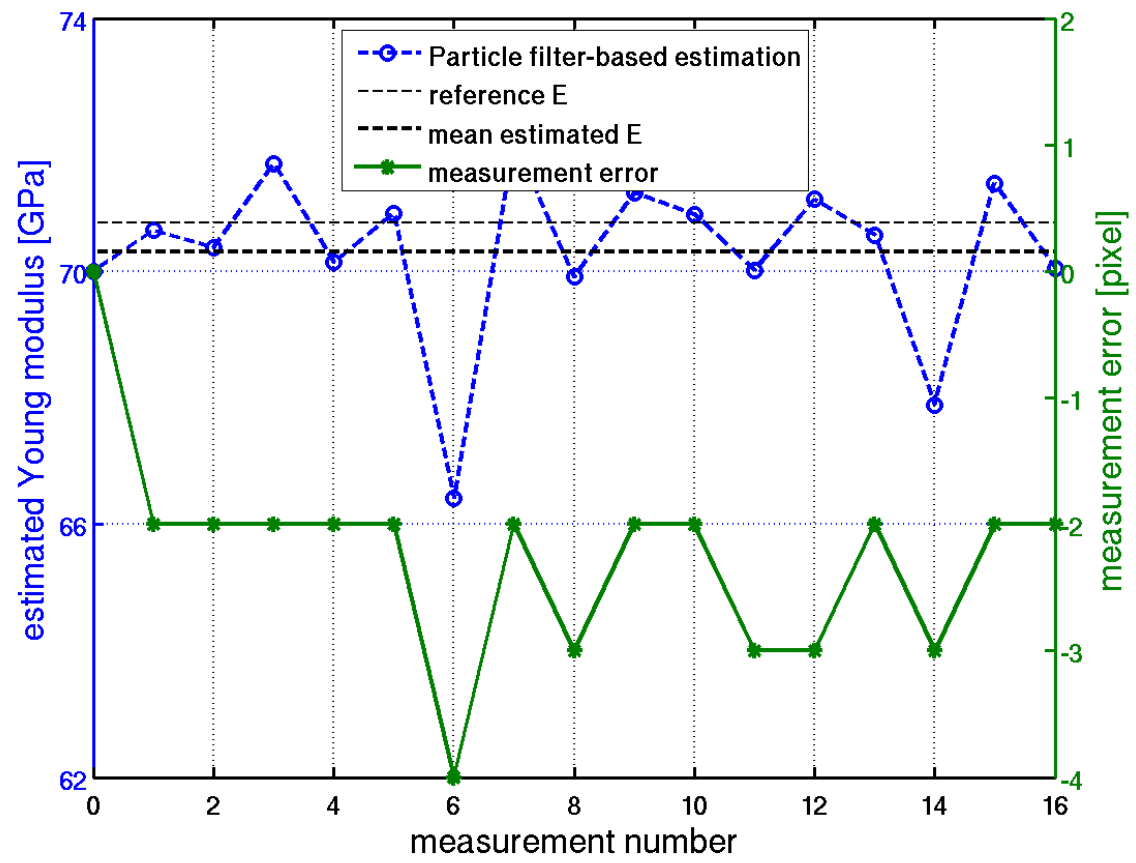

Fig. 9. Plot of sequential estimation of Young modulus using particle filter, in case of horizontal force (first experiment) 


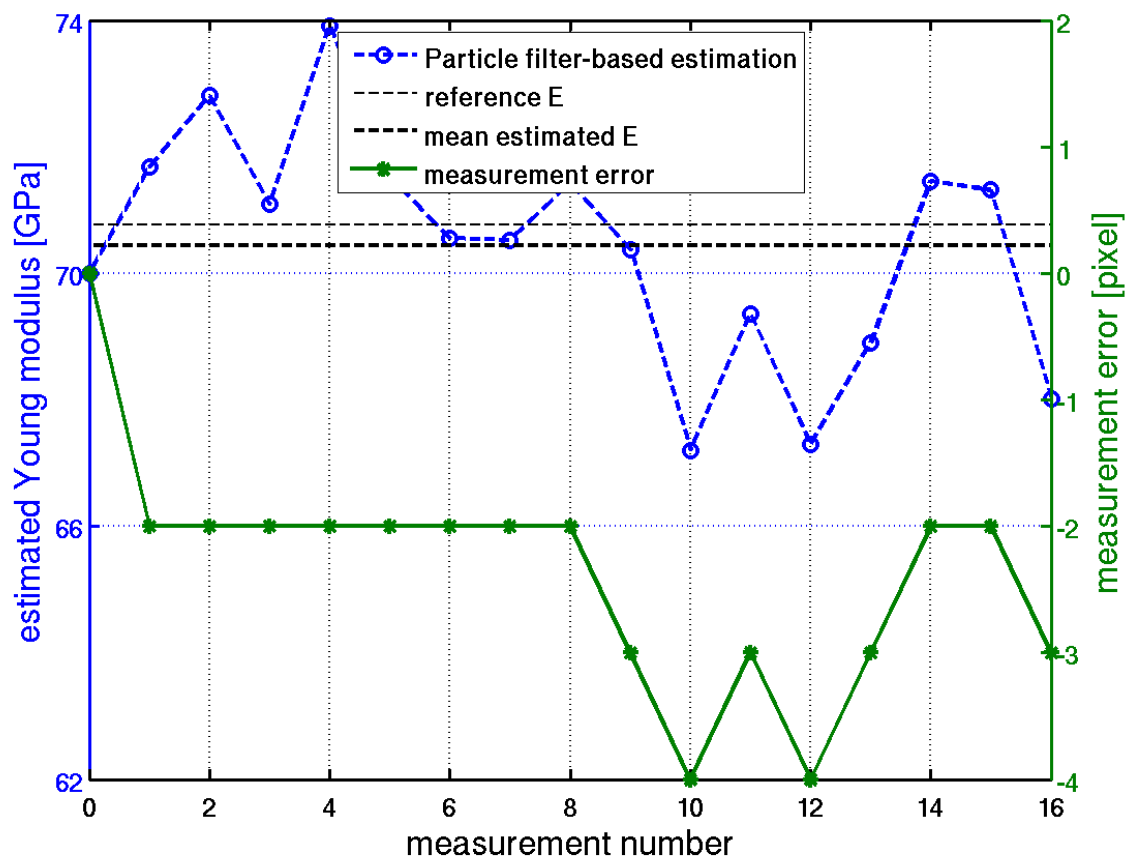

Fig. 10. Plot of sequential estimation of Young modulus using particle filter, in case of horizontal force (second experiment)

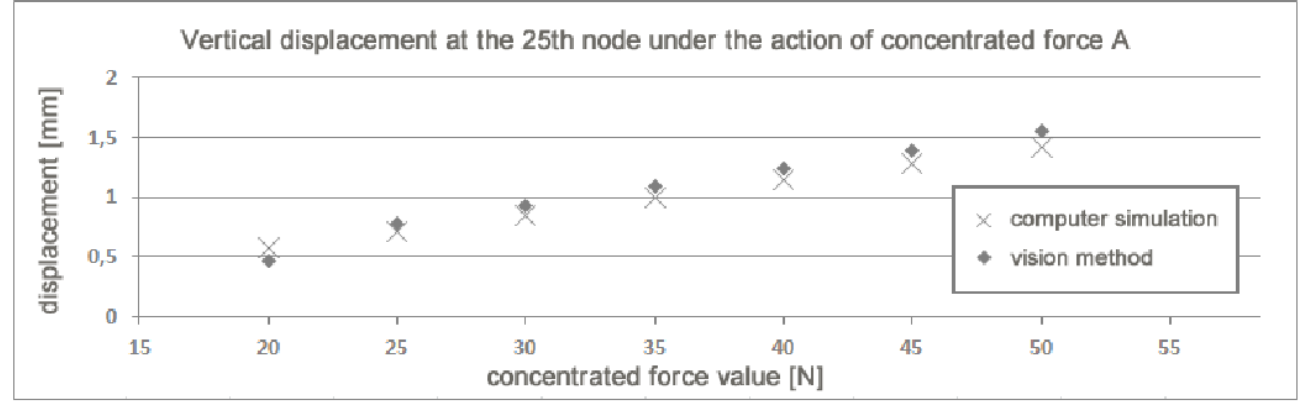

Fig. 11. Validation ofq FE model updating using measured and computed vertical displacements at $25^{\text {th }}$ node under action of vertical load

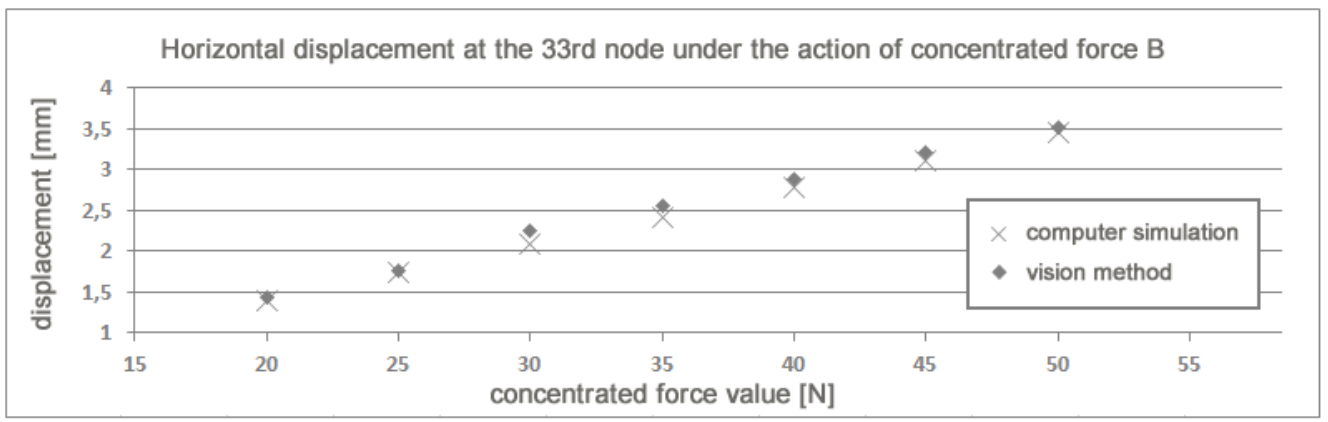

Fig. 12. Validation of FE model updating using measured and computed horizontal displacements at $33^{\text {th }}$ node under action of horizontal load 


\section{FINAL REMARKS}

In this paper an example application of the Monte Carlo filter for sequential finite element model updating was presented. The updating procedure was based on measurements of structure displacements using computer vision techniques. In particular the problem of identification of Young modulus for an aluminum laboratory-scale frame was investigated.

Two cases of quasi-static concentrated force acting on the frame were considered. It was shown that the proposed sequential approach using particle filter together with computer vision-based displacement measurements and FEM-based predicted displacements are able to successfully solve the material parameter identification problem. In both cases, the estimated values of Young modulus were close to the reference value.

Moreover, the comparison of PF-based identification result with Kalman filter solution verified successfully our implementation of the particle filter. It will allows us to test our approach to solving nonlinear identification problems.

\section{Acknowledgments}

The Authors would like to thank Bartosz Miller from the Department of Structural Mechanics of Rzeszów University of Technology for sharing his aluminum frame. The second Author would like also to acknowledge that the research was partially supported by the European Union through the European Social Fund within the project Cracow University of Technology development program - top quality teaching for the prospective Polish engineers University of the 21 st century (contract no. UDA-POKL.04.01.01-00-029/10-00).

\section{References}

Babuška I., Nobile F., Tempone R. 2008, A systematic approach to model validation based on bayesian updates and prediction related rejection criteria. Computer Methods in Applied Mechanics and Engineering, 197(29), pp. 2517-2539.

Bradski G., Kaehler A. 2008, Learning OpenCV: Computer vision with the OpenCV library. O'Reilly.

Ching J., Beck J.L., Porter K.A. 2006, Bayesian state and parameter estimation of uncertain dynamical systems. Probabilistic Engineering Mechanics, 21(1), pp. 81-96.

Furukawa T., Pan J.W. 2010, Stochastic identification of elastic constants for anisotropic materials. International Journal for Numerical Methods in Engineering, 81(4), pp. 429-452.

Maier G., Bocciarelli M., Bolzon G., Fedele R. 2006, Inverse analyses in fracture mechanics, International Journal of Fracture, 138, pp. 47-73.

Mares C., Mottershead J.E., Friswell M.I. 2006, Stochastic model updating: part 1 -theory and simulated example. Mechanical Systems and Signal Processing, 20(7), pp. 1674-1695.

Miller B. 2011, Application of neural networks for structure updating. Computer Assisted Mechanics and Engineering Sciences, 18, pp. 191-203.

Nasrellah H.A., Manohar C.S. 2011, Finite element method based monte carlo filters for structural system identification. Probabilistic Engineering Mechanics, 26(2), pp. 294-307.

Oden T., Moser R., Ghattas O. 2010, Computer predictions with quantified uncertainty, part I. SIAM News, 43(9), pp. 1-4.

Roy C.J., Oberkampf W.L. 2011, A comprehensive framework for verification, validation, and uncertainty quantification in scientific computing. Computer Methods in Applied Mechanics and Engineering, 200(25), pp. 2131-2144.

Russel S., Norvig P. 2010, Artificial Intelligence: A Modern Approach. Prentice Hall, 3rd ed.

Tekieli M., Słoński M. 2013, Computer vision based method for real time material and structure parameters estimation using digital image correlation, particle filtering and finite element method. In Artificial Intelligence and Soft Computing, volume 7894 of Lecture Notes in Computer Science, pp. 624-633. Springer. 